\title{
Safety and therapeutic potential of human bone marrow-derived mesenchymal stromal cells in regenerative medicine
}

\author{
Ashwini P. Aithal ${ }^{1}$, Laxminarayana K. Bairy ${ }^{2}$, Raviraja N. Seetharam ${ }^{3}$ \\ ${ }^{1}$ Department of Anatomy, Melaka Manipal Medical College (Manipal Campus), Manipal Academy of Higher Education, Manipal, India; ${ }^{2}$ Department \\ of Pharmacology, RAK College of Medical Sciences, RAK Medical and Health Sciences University, Ras Al Khaimah, UAE; ${ }^{3}$ Stempeutics Research \\ Pvt. Ltd, Manipal, Karnataka, India \\ Contributions: (I) Conception and design: AP Aithal; (II) Administrative support: Manipal Academy of Higher Education; (III) Provision of study \\ materials or patients: None; (IV) Collection and assembly of data: AP Aithal; (V) Data analysis and interpretation: All authors; (VI) Manuscript \\ writing: All authors; (VII) Final approval of manuscript: All authors. \\ Correspondence to: Ashwini P. Aithal. Assistant Professor, Department of Anatomy, Melaka Manipal Medical College (Manipal Campus), Manipal \\ Academy of Higher Education, Manipal, Karnataka 576104, India. Email: ashwini.anat@gmail.com.
}

\begin{abstract}
Regenerative medicine is considered as an alternative approach to healthcare. Owing to their pluripotent abilities and their relative lack of ethical and legal issues, adult stem cells are considered as optimal candidates for use in the treatment of various diseases. Bone marrow-derived mesenchymal stem cells are among the most promising candidates for clinical applications as they have expressed a higher degree of plasticity in vitro. Many investigators have begun to examine how bone marrow stem cells might be used to rebuild damaged tissues. The systemic administration of cells for therapeutic applications requires efficient migration and homing of cells to the target site. Cell adhesion molecules and their ligands, chemokines, extracellular matrix components and specialized bone marrow niches all participate in the proper regulation of this process. MSCs suppress the pathophysiological process that is mediated by chronic inflammation and contributes to a modification of the microenvironment and tissue regeneration. Due to the intricacy of the mesenchymal stem cell, there is ever-increasing amount of data emerging about their migration and regenerative mechanisms. Many factors influence MSC mobilization and their homing to injured tissues. This review summarizes the current clinical and pre-clinical data available in literature regarding the use of MSC in tissue repair and their prospective therapeutic role in various diseases and the underlying repair mechanisms will be discussed.
\end{abstract}

Keywords: Stem cells; bone marrow stromal cells; therapeutics; safety

Received: 24 October 2020; Accepted: 24 March 2021; Published: 11 May 2021.

doi: $10.21037 /$ sci-2020-036

View this article at: http://dx.doi.org/10.21037/sci-2020-036

\section{Introduction}

Therapies involving stem cell transplantation have shown promising potential in repairing and regeneration of injured organs and tissues in various degenerative diseases and is a captivating area of modern-day biology. Adult stem cells exist in all adult tissues and are defined as undifferentiated cells within a population of differentiated cells. Sources of stem cells include, blood, bone marrow, adipose tissue, umbilical cord, amniotic fluid etc. The prime function of these stem cells is to maintain the tissue and also repair the cells in which they are found (1). They are responsible for replacement of dead apoptotic cells with new ones, thereby maintaining tissue homeostasis.

Bone marrow is the chief source of adult stem cells which is the most intensively investigated cell type for cellular therapies. Bone marrow is an abundant source of different types of stem cell population, most important among them being the mesenchymal stem cells (MSCs). For any cell to be termed as MSC, they should have the ability to replicate 
and exhibit tri-lineage plasticity to cells like adipocytes, chondroblats, and osteoblasts (2). Human bone marrowderived mesenchymal stromal cells (BM-MSCs) are spindle-shaped cells which aretab positive for mesenchymal receptors such as $\mathrm{SH} 2, \mathrm{SH} 3, \mathrm{CD} 29, \mathrm{CD} 44, \mathrm{CD} 90, \mathrm{CD} 71$, CD106, CD120a, CD124, CD73, and CD105. MSC transplantation has many advantages such as: (I) MSCs are not a derivative of somatic cells and are superior regarding ethical concerns related to the treatment of diseases; (II) MSCs can be obtained easily from a variety of tissues, such as bone marrow, umbilical cord blood, peripheral blood, adipose tissue and can be expanded in culture; (III) MSCs can differentiate into an extensive variety of cell types (3).

Given their emerging importance, this review aims to provide an overview of safety, homing potential and ongoing work aimed at understanding the potential of these cells in regenerative medicine.

\section{Origin of stem cells}

A stem cell can be obtained from an embryo or adult. Embryonic stem cells are the cells of the inner cell mass of the blastocyst. These cells can eventually differentiate into multiple tissue lineages $(4,5)$. Because of its human origin, use of embryonic stem cells in research is a topic with moral, legal, and ethical issues. Teratoma formation, transplant rejection, and ethical concerns are a few hurdles that embryonic stem cell researchers are facing today. On the other hand, use of adult stem cells for research and treatment is less of an issue since it does not require the destruction of embryos. An adult stem cell is found in numerous adult tissues including bone marrow, blood, neurons, skeletal muscle, skin, etc. and support cellular regeneration of the tissue to which they belong (6-8).

\section{General classification of stem cells}

\section{Stem cells are classified based on their potency as follows:}

\section{Totipotent stem cell}

Totipotent stem cells can differentiate into any cells in the body including extraembryonic cells. An example is a zygote. It is totipotent because its cells have unlimited replication abilities. Totipotent cells can form somatic stem cells, progenitor cells and primitive germline cells (9).

\section{Pluripotent stem cell}

These stem cells can differentiate into several different types of other cell types. In pluripotent stem cells, specialization is minimal. They are characterized by self-renewal and a differentiation potential for all cell types (10). Stem cells obtained from embryonic tissues or stem cells from aborted fetuses are examples for pluripotent cells.

\section{Multipotent stem cell}

Multipotent cells can differentiate into restricted type of specialized cell types, i.e., these stem cells can characteristically differentiate into cell of a particular group or kind. Adult Hematopoietic Stem cells, mesenchymal stem cells, adipose tissue is also a source of multipotent stem cells (11).

\section{Oligopotent stem cell}

This group of stem cells can differentiate into specific cell types, like the lymphoid or myeloid cells.

\section{Unipotent stem cell}

Unipotent stem cells have infinite differentiation abilities but can only form a single type of cell or tissue. Skin cells are examples for unipotent stem cells. Most of the epithelial tissues are capable of self-renewal throughout life due to the presence of such unipotent cells (12).

\section{Mesenchymal stem cells (MSCs)}

MSCs (or stromal cells) are the term used to describe the collection of poorly defined multipotent, heterogeneous population of bone marrow cells. Mesenchymal stem cells are self-renewable, multipotent progenitor cells which have the ability to differentiate, under adequate stimuli, into several mesenchymal lineages (13).

\section{Classification of MSCs}

MSCs are found in almost all tissues. Based on the source of cells, MSCs are classified as follows.

\section{Bone marrow-derived MSCs (BM-MSCs)}

Bone marrow mesenchymal cells were first well-defined by Friedenstein $e t$ al. (14). They are often selected as the gold standard and the most extensively studied stem cell type. Aspiration of bone marrow from healthy donors is an invasive procedure. Frequently used method for the generation of MSCs from BM is density gradient centrifugation (15) and then the cells are cultured. BMMSCs are morphologically larger than other cell types 
(16). MSCs from bone marrow are generally cultured in Dulbecco's modified Eagle's media (DMEM)/DMEM-F12 supplemented with $10 \%$ fetal bovine serum (FBS). BMMSCs are positive for markers like CD73, CD90, CD105, STRO-1 and negative for CD14, CD34, CD45, HLA-DR $(17,18)$. BM-MSCs are easily isolated, can be expanded and harvested. They are abundantly available in bone marrow and can differentiate into chondrogenic and osteogenic lineages at a higher rate when compared to other types of MSCs (19).

\section{Adipose tissue-derived MSCs (AT-MSCs)}

These cells are often isolated from homogenized adipose tissue material obtained during procedures such as lipoplasty, liposuction, or lipectomy (20). AT-MSCs have said to possess higher proliferation capacity than BMMSCs (21). MSCs which are isolated from the adipose tissue are then cultured in DMEM/DMEM-Low glucose, supplemented with $10 \%$ FBS (22).

\section{Cord blood-derived MSCs}

Blood collected from the umbilical cord of a baby is a rich source of stem cells, first described by Erices et al. (23) and is isolated using Ficoll gradient centrifugation method (24). Chances of these stem cells being rejected by the host tissue is rare. This, might be because the cord blood cells do not have cell-surface molecules which are recognized and attacked by the host's immune system.

\section{Wharton's Jelly MSCs}

These cells can be labelled as an amenable, abundant, and economical source of MSCs which has shown promising use in tissue regenerative. Wharton's jelly is a gelatinous tissue present within the umbilical cord. Fresh umbilical cords from full-term births are obtained and processed using proper standardization process (25). MSCs from Wharton's jelly are cultured in DMEM supplemented with 10\% FBS. Advantages of these cells include: ease of availability, in vitro expandability, differentiation abilities, immune-evasion, and immune-regulation capacities (26).

\section{Placenta-derived MSCs}

Placenta-derived MSCs are obtained and cultured from the cotyledons on the maternal side of placenta. The distinctive properties of these stem cells include: cells are widely available without any ethical concerns. Cells can be cultured without compromising cell cycle/apoptosis pattern and endogenous gene expression pattern (27). PD-MSCs are obtained by enzymatic digestion method and are generally cultured in DMEM-LG supplemented with 10\% FBS.

\section{Amniotic fluid-derived MSCs}

These cells were first reported by Prusa et al. (28). Amniotic membrane and amniotic fluid contain sub-population of MSCs. These cells can also be isolated by enzymatic digestion method and are generally cultured in $\alpha$-Minimal Essential Medium ( $\alpha$-MEM)/DMEM-F12 with $10 \%$ FBS.

MSCs isolated and cultured from fetal tissues have the advantage of wide availability, low oncogenicity, no ethical concerns, high expandability and low risk of contamination $(29,30)$.

\section{Synovial fluid MSCs}

Synovial fluid has considerable regeneration capacity which is expressed during its reappearances following surgical synovectomy (31). Synovial MSC are isolated by the method of Ficoll density gradient and are cultured in $\alpha$-MEM supplemented with $10 \%$ FBS. There appears to be a potential role of these MSCs in ligament regeneration when compared to BM-MSCs (32).

\section{Dental pulp MSCs}

The search for easily accessible MSCs other than bone marrow has originated the investigations in dental tissues cells. At first, MSC like cells were isolated from human dental pulp and termed as postnatal dental pulp stem cells (DPSCs) (33). MSCs derived from dental pulp are generally cultured in $\alpha$-MEM supplemented with $10 \%$ FBS or FCS.

\section{Peripheral blood-derived MSCs}

These are one of the easily accessible sources of stem cells and form the alternative to BM-MSCs. Cells isolated from peripheral blood shows all basic MSCs characteristics and exhibit similar morphology as BMMSC. Its differences were only in the clonogenic efficiency and the immune phenotype (34). PB-MSCs are isolated by Ficoll-Paque density-gradient separation method using the peripheral blood and are cultured in $\alpha$-MEM supplemented with $10 \%$ newborn calf serum (NBCS).

\section{MSCs derived from other sources such as the} bronchoalveolar lavage (BAL) fluid, atrium tissue from heart, spleen tissue and perirenal fat tissue Mesenchymal stem cells are also derived from human lung allografts. Cells obtained from bronchoalveolar Lavage fluid are maintained in a culture medium of glucose DMEM 
supplemented with $10 \%$ FBS. Hoogduijn et al., reported the isolation and characterization of MSCs from the human heart, spleen, and perirenal adipose tissue (35). MSCs obtained from such tissues are similar to those derived from bone marrow and express cell-surface markers CD90, CD166, CD105 and HLA class I.

\section{Safety assessment of BM-MSCs}

The safety of BM-MSCs treatments must be established in animal models before its clinical application in humans. Although MSCs transplantation is safe, numerous studies have also reported the risks associated with the mesenchymal stem cells treatments. Reports have presented that MSCs can induce sarcoma or enable the growth of the tumor (36). Hence, it has been postulated that comprehensive preclinical safety and toxicity studies of MSCs are required before their use in clinical trials.

$\mathrm{Ra}$ et al. found that administration of adipose-derived mesenchymal stem cells in rats is safe (37). They reported that subcutaneous administration of high dose of adiposederived MSCs till $2 \times 10^{8}$ cells $/ \mathrm{kg}$ b. wt in mice showed no evidence of tumor formation. In another study, systemic administration of BM-MSCs was found safe with no change in the overall health or immune status of the rat (38). It is apparent that a single administration of allogeneic BMMSCs did not induce proinflammatory responses in the experimental animals. Aithal et al., have showed in their study that BM-MSCs administration did not alter the food and water intake behavior of the rats and did not have any undesirable effect on its body weight (39). Gao et al., also observed that intravenous administered MSC accumulated initially in the lungs and gradually redistributed to liver, spleen, kidney, and bone marrow before disappearing from the circulation in rodents (40). The findings of Prather et al., demonstrated that intramuscular administered MSCs persisted only at the injection site and did not localize to other organs (41). Rengasamy et al., and other researchers believe that intravenous administration of BM-MSCs is more efficient and safer compared to other routes (42). MSCs have the capacity of expanding and culturing longterm in vitro, with very minimal changes in their function, morphology and phenotype (43).

\section{Biodistribution and homing of BM-MSCs}

The therapeutic benefit of BM-MSCs can be comprehended through its homing efficiency to the specific target site. The tracking of BM-MSCs after intravenous administration has been explored by some studies in animals and humans. The labeling methodologies which are frequently used to label the culture-expanded BM-MSCs include: radioactive labeling, labeling with fluorescent dyes and contrast agents, using donor cell-specific DNA markers like microsatellites or transduction with reporter genes (44-47). These labeling methods were designed to detect only the short-term homing capacity of MSCs. The summary of the results of these studies indicate that: MSCs distribute to a variety of tissues and were noticeable at low or very low frequencies in those tissues after transplantation with highest occurrences in lungs, followed by liver and spleen. Cell adhesion molecules and their ligands, chemokines, extracellular matrix components and specialized bone marrow niches all participate in the proper regulation of this process. Studies have shown that MSCs were localized to the infarct region and improved ventricular function (48) and that corticosteroids are involved in MSCs migration (49).

In summary, there is some evidence regarding the biodistribution of BM-MSCs to organs, but the underlying mechanisms are mostly unclear. Few reports also mention that MSCs is not very efficacious as only a small number of cells reach the target tissue/organ and remain there after systemic administration. This can be attributed to many factors like: (I) low expression of homing molecules and failure of molecules to express during the expansion process (50,51); (II) the heterogeneity of MSCs in cultures and heterogeneous expression of MSCs derived from different tissues (52). Mode of administration of cells or the target tissue could be modified in order to attract the MSCs (53).

\section{Potential use of BM-MSCs in regenerative medicine for treatment of various diseases}

MSC is well tolerated and does not suffer from host versus graft response after transplant (54). Here we discuss the results of previous studies which demonstrate the ability of BM-MSCs to differentiate into various tissues/organs.

\section{Liver disease}

In-vitro differentiation of MSCs to liver hepatocytes has been proven (55). In vivo experiments have also confirmed the differentiation of MSCs into hepatocytes $(56,57)$. In the study of Sato et al., human BM-MSCs were differentiated into hepatocyte-like cells when xenografted directly into 
rat livers (58). Improvement in liver fibrosis after MSCs transplantation was also reported and has been attributed to the capacity of MSCs to reduce the high levels of oxidative stress and release of many paracrine factors by them (59). Phase I and Phase II human clinical trials for treating liver cirrhosis suggest that differentiated and undifferentiated MSC transplantation was effective and improved liver functions (60-62). MSCs have found to produce many growth factors and cytokines, which exerts a paracrine effect in the necrotic tissue. MSCs also exert a suppressive effect on natural killer cells thereby enhancing their therapeutic effects (3).

\section{Cardiac disease}

Recently, researches have been done using MSCs as a therapeutic strategy for ischemic heart diseases and the data obtained from these in vitro studies have been translated into clinical trials (63). MSCs transplanted into the rat myocardium acted through the combined effect of endogenous cardio myogenesis and angiogenesis $(64,65)$. MSCs enhanced the survival of existing myocytes by paracrine mechanisms in mice (66). Studies done by Shake $e t a l$., and Toma et al., have successfully reported that injected MSCs engrafted into scarred myocardium and expressed cardiomyocyte markers like desmin, $\alpha$-actin, myosin and tropomyosin heavy chain $(67,68)$. Based on rigorous preclinical studies, clinical trials have also been initiated for MI and ischemic cardiomyopathy. Intravenous and intracoronary injections of MSCs in subacute and acute MI demonstrated a reduction in ventricular arrhythmias, improvement in perfusion defects and improved pulmonary function $(69,70)$.

\section{Kidney diseases}

Transplanted BM-MSCs accelerated the process of glomerular healing in experimental rat model of glomerulonephritis (71). Studies have shown that injected MSCs reduced interstitial fibrosis, improved progression of chronic kidney disease $(72,73)$. MSCs protect against acute renal injury by promoting the recovery and functional alterations of tubular epithelial cells (74). MSCs are advantageous as they provide a local pro survival environment for the damaged kidney, which is useful in preserving the podocyte viability, reduce glomerular inflammation and sclerosis (75), thereby, MSCs enhance renal repair $(76,77)$.

\section{Bone and cartilage}

The differentiation potential of BM-MSCs into bone cells make them successful in managing and treating bone fractures (78). It was found that mismatched allogeneic MSCs regenerated bone without producing an immunologic response. This raised the possibility of starting allogeneic MSCs banks for bone regeneration (79). Another study suggested that at least 1000 or more MSCs per $\mathrm{cm}^{3}$ are required for bone repair (80). There has been some hindrance for the use of MSCs in bone repair due to inadequate supply of autologous bone grafts and the unsuitability of allografts.

\section{Nervous system}

BM-MSCs have been effective in treating neurodegenerative disorders through enhanced neurogenesis, peripheral nerve regeneration and abnormal protein aggregate clearance (81,82). MSCs possess neurotrophic factors and cytokines which activate neurogenesis, neuroprotection and immunomodulation in neurons, astrocytes, and oligodendrocytes. MSC can also inactivate cell death and diminish free radicals (83). Transplanted MSCs differentiated into neural stem cells and improved the functional recovery of two patients with chronic spinal injury (84), while significant improvement in nerve conduction velocities was observed in patients suffering from metachromatic leukodystrophy and Hurler syndrome (85).

\section{Autoimmune diseases}

BM-MSCs exhibit the property of modulating the functions of several immune effector cells, which makes them appropriate treatment option for few autoimmune diseases (86). Therapeutic benefits of MSC have been proposed for Crohn's disease (87), systemic lupus erythematosus $(88,89)$ rheumatoid arthritis (90) and multiple sclerosis (91). However, more largescale clinical studies are necessary to obtain actual results.

The promising results of pre-clinical and clinical studies suggest that donor allogeneic BM-MSCs infusion might be safe, feasible treatment and may be related to the reversal of disease pathophysiology in several pathologies.

\section{Mechanisms concerned with the therapeutic effects of BM- MSCs}

According to some researchers, the therapeutic abilities 
of BM-MSCs are largely attributed to the following mechanisms: (I) differentiating into various cell lineages (trans-differentiation of BM-MSCs), (II) MSCs have immunomodulatory properties by secreting antiinflammatory cytokine, (III) induction of endogenous regeneration by BM-MSCs.

\section{Trans-differentiation of BM-MSCs into tissues}

Transdifferentiation is a process wherein a cell type which is committed to a specific developmental lineage switches to another cell type of a different lineage. This process is known genetic reprogramming. Studies have shown that MSCs go through a phenotypic change, express the genes which are usually expressed in tissues, fulfill some essential metabolic functions and thereby, MSC can transdifferentiate into the cells of various tissues in vitro and in vivo (92-95). The specific gene signaling pathways and gene expression is ingeniously regulated by numerous transcription factors secreted by MSC and is also influenced by the tissue microenvironment (96).

\section{Immunomodulation by BM-MSCs}

MSCs therapeutic potential during the treatment of any disease might actually result from immunomodulation. BMMSCs supress the expression of many proinflammatory molecules [interleukin (IL)-1 $\beta$, IL-12, TNF- $\alpha$, and interferon- $\gamma$ ] and also secrete anti-inflammatory factors, shifting the immune response pattern towards a protective type, modifying the microenvironment where activated $\mathrm{T}$ cells are unable to proliferate and die by apoptosis $(97,98)$. Immunosuppressive properties of MSC can also be owed to the Nitric oxide synthase and heme oxygenase- 1 molecules which are secreted by them $(99,100)$.

\section{Induction of endogenous regeneration by BM-MSCs}

MSCs secrete a wide range of trophic factors, as well as vascular endothelial growth factor, fibroblast growth factor, platelet-derived growth factor, HGF, TGF- $\beta$, IGF-1, and epidermal growth factor (101). These growth factors act either by altering the intracellular signal pathways or by inducing other cells to secrete additional bioactive factors from the injured tissue microenvironment. Therefore, it has been anticipated that MSCs have a catalytic role in tissue regeneration. MSCs can modify the microenvironment by secreting factors that would prevent parenchymal cells from dying, reduce apoptosis, induce angiogenic and antioxidative effects (102).

Although the delicate mechanism governing the process of tissue regeneration is very complicated and far from clear, it can be assumed that the beneficial effects of BMMSCs varies with the nature and degree of tissue injury and depends on many factors like time-frame of MSCs application, donor age, tissue origin, cell densities, cell passage numbers, different experimental models and so on.

\section{Conclusions}

MSC-based treatments have made great progress over the last few decades. However, the clinical trials with mixed and contradictory results are preventing the advancement of MSCs into daily clinical application. There are several problems in cell transplantation which must be considered. First, the frequency with which the engrafted MSCs differentiate after transplantation remains unsatisfactory. Second, regardless of the critical benefits of MSC-based therapy, safety issues remain a concern, particularly the long-term effect of transplantation on immune function and the risk of tumorigenicity. Third, MSCs may display a profibrogenic potential in the process of treating any disease. These are the undesirable effects which should be reasonably addressed when using MSCs for the therapeutic purposes. A standardized approach has not yet been established to evaluate the safety and toxicity of MSCs in vivo. Quality control and clinical grade production of MSC are necessary before in vivo application of MSCs. Optimum dose and precise administration time for MSC should be formulated depending on the harshness of each disease. Therefore, further studies are necessary to understand the benefits of BM-MSCs as therapeutics in clinical settings. Large scale preclinical and clinical trials are required to verify the safety and therapeutic potential of BM-MSCs in regenerative medicine.

\section{Acknowledgments}

Funding: None.

\section{Footnote}

Conflicts of Interest: All authors have completed the ICMJE uniform disclosure form (available at http://dx.doi. org/10.21037/sci-2020-036). The authors have no conflicts of interest to declare. 
Ethical Statement: The authors are accountable for all aspects of the work in ensuring that questions related to the accuracy or integrity of any part of the work are appropriately investigated and resolved.

Open Access Statement: This is an Open Access article distributed in accordance with the Creative Commons Attribution-NonCommercial-NoDerivs 4.0 International License (CC BY-NC-ND 4.0), which permits the noncommercial replication and distribution of the article with the strict proviso that no changes or edits are made and the original work is properly cited (including links to both the formal publication through the relevant DOI and the license). See: https://creativecommons.org/licenses/by-nc-nd/4.0/.

\section{References}

1. Jiang Y, Jahagirdar B, Reinhardt R, et al. Pluripotency of mesenchymal stem cells derived from adult marrow. Nature 2002;418:41-9.

2. Dominici M, Le Blanc K, Mueller I, et al. Minimal criteria for defining multipotent mesenchymal stromal cells. The International Society for Cellular Therapy position statement. Cytotherapy 2006;8:315-7.

3. Liu WH, Song FQ, Ren LN, et al. The multiple functional roles of mesenchymal stem cells in participating in treating liver diseases. J Cell Mol Med 2015;19:511-20.

4. Evans MJ and Kaufman MH. Establishment in culture of pluripotential cells from mouse embryos. Nature 1981;292:154-6.

5. Martin GR. Isolation of a pluripotent cell line from early mouse embryos cultured in medium conditioned by teratocarcinoma stem cells. Proc Natl Acad Sci U S A 1981;78:7634-8.

6. Dzierzak $\mathrm{E}$. The emergence of definitive hematopoietic stem cells in the mammal. Curr Opin Hematol 2005;12:197-202.

7. Gage FH. Mammalian neural stem cells. Science 2000;287:1433-8.

8. Taylor G, Lehrer MS, Jensen PJ, et al. Involvement of follicular stem cells in forming not only the follicle but also the epidermis. Cell 2000;102:451-61.

9. Weissman IL. Stem cells: units of development, units of regeneration, and units in evolution. Cell 2000;100:157-68.

10. Horie M, Ito A. A Genetically Engineered STO Feeder System Expressing E-Cadherin and Leukemia Inhibitory Factor for Mouse Pluripotent Stem Cell Culture. J Bioprocess Biotechniq 2011;1. doi: 10.4172/2155-9821.
S3-001

11. Zuk PA, Zhu M, Ashjian P, et al. Human adipose tissue is a source of multipotent stem cells. Mol Biol Cell 2002;13:4279-95.

12. Blanpain C, Horsley V, Fuchs E. Epithelial stem cells: turning over new leaves. Cell 2007;128:445-58.

13. Sollazzo V, Palmieri A, Girardi A, et al. Trabecular Titanium Induces Osteoblastic Bone Marrow Stem Cells Differentiation. J Biotechnol Biomaterial 2011;1:102.

14. Friedenstein AJ, Gorskaja JF, Kulagina NN. Fibroblast precursors in normal and irradiated mouse hematopoietic organs. Exp Hematol 1976;4:267-74.

15. Pittenger MF, Mackay AM, Beck SC, et al. Multilineage potential of adult human mesenchymal stem cells. Science 1999;284:143-7.

16. Peng L, Jia Z, Yin $X$, et al. Comparative Analysis of Mesenchymal Stem Cells from Bone Marrow, Cartilage, and Adipose Tissue. Stem Cells Dev 2008;17:761-73.

17. Otsuru S, Hofmann TJ, Olson TS, et al. Improved isolation and expansion of bone marrow mesenchymal stromal cells using a novel marrow filter device. Cytotherapy 2013;15:146-153.

18. Mamidi MK, Nathan KG, Singh G, et al. Comparative cellular and molecular analyses of pooled bone marrow multipotent mesenchymal stromal cells during continuous passaging and after successive cryopreservation. J Cell Biochem 2012;113:3153-64.

19. Gimble JM, Katz AJ, Bunnell BA. Adipose-derived stem cells for regenerative medicine. Circ Res 2007;100:1249-60.

20. Kuhbier JW, Weyand B, Radtke C, et al. Isolation, characterization, differentiation, and application of adipose-derived stem cells. Adv Biochem Eng Biotechnol 2010;123:55-105.

21. Kern S, Eichler H, Stoeve J, et al. Comparative Analysis of Mesenchymal Stem Cells from Bone Marrow, Umbilical Cord Blood, or Adipose Tissue. Stem Cells 2006;24:1294-301.

22. Pendleton C, Li Q, Chesler DA, et al. Mesenchymal stem cells derived from adipose tissue vs bone marrow: in vitro comparison of their tropism towards gliomas. PLoS One 2013;8:e58198.

23. Erices A, Conget P, Minguell JJ. Mesenchymal progenitor cells in human umbilical cord blood. Br J Haematol 2000;109:235-242.

24. Kögler G, Sensken S, Airey JA, et al. A new human somatic stem cell from placental cord blood with intrinsic pluripotent differentiation potential. J Exp Med 2004;200:123-35. 
25. Peng J, Wang Y, Zhang L, et al. Human umbilical cord Wharton's jelly-derived mesenchymal stem cells differentiate into a Schwann-cell phenotype and promote neurite outgrowth in vitro. Brain Res Bull 2011;84:235-43.

26. Semenov O, Olah MJ, Stefanovic D. Mechanism of diffusive transport in molecular spider models. Phys Rev E Stat Nonlin Soft Matter Phys 2011;83:021117.

27. Sabapathy V, Ravi S, Srivastava V, et al. Long-Term Cultured Human Term Placenta-Derived Mesenchymal Stem Cells of Maternal Origin Displays Plasticity. Stem Cells Int 2012;2012:174328.

28. Prusa AR, Hengstschlager M. Amniotic fluid cells and human stem cell research: a new connection. Med Sci Monit 2002;8:RA253-7.

29. Beeravolu N, McKee C, Alamri A, et al. Isolation and Characterization of Mesenchymal Stromal Cells from Human Umbilical Cord and Fetal Placenta. J Vis Exp 2017;(122):55224.

30. Margossian T, Reppel L, Makdissy N, et al. Mesenchymal stem cells derived from Wharton's jelly: comparative phenotype analysis between tissue and in vitro expansion. Biomed Mater Eng 2012;22:243-54.

31. Ostergaard M, Ejbjerg B, Stoltenberg M, et al. Quantitative magnetic resonance imaging as marker of synovial membrane regeneration and recurrence of synovitis after arthroscopic knee joint synovectomy: a one year follow up study. Ann Rheum Dis 2001;60:233-6.

32. McGonagle D, Jones E. A potential role for synovial fluid mesenchymal stem cells in ligament regeneration. Rheumatology 2008;47:1114-6.

33. Gronthos S, Mankani M, Brahim J, et al. Postnatal human dental pulp stem cells (DPSCs) in vitro and in vivo. Proc Natl Acad Sci U S A 2000;97:13625-30.

34. Trivanović D, Kocić J, Mojsilović S, et al. Mesenchymal stem cells isolated from peripheral blood and umbilical cord Wharton's jelly. Srp Arh Celok Lek 2013;141:178-86.

35. Hoogduijn MJ, Crop MJ, Peeters AM, et al. Human heart, spleen, and perirenal fat-derived mesenchymal stem cells have immunomodulatory capacities. Stem Cells Dev 2007;16:597-604.

36. Zimmerlin L, Donnenberg AD, Rubin JP, et al. Regenerative Therapy and Cancer: In Vitro and In Vivo Studies of the Interaction Between Adipose-Derived Stem Cells and Breast Cancer Cells from Clinical Isolates. Tissue Eng Part A 2011;17:93-106.

37. Ra JC, Shin IS, Kim SH, et al. Safety of intravenous infusion of human adipose tissue-derived mesenchymal stem cells in animals and humans. Stem Cells Dev
2011;20:1297-308.

38. Lee KJ, Jeong HG. Protective effect of Platycodix radix on carbon tetrachloride-induced hepatotoxicity. Food Chem Toxicol 2002;40:517-25.

39. Aithal AP, Bairy LK, Seetharam RN. Safety Assessment of Human Bone Marrow derived Mesenchymal Stromal Cells Transplantation in Wistar Rats. J Clin Diagn Res 2017;11:FF01-3.

40. Gao J, Dennis JE, Muzic RF, et al. The Dynamic in vivo Distribution of Bone Marrow-Derived Mesenchymal Stem Cells after Infusion. Cells Tissues Organs 2001;169:12-20.

41. Prather WR, Toren A, Meiron M, et al. The role of placental-derived adherent stromal cell (PLX-PAD) in the treatment of critical limb ischemia. Cytotherapy 2009;11:427-34.

42. Rengasamy M, Gupta PK, Kolkundkar U, et al. Preclinical safety \& toxicity evaluation of pooled, allogeneic human bone marrow-derived mesenchymal stromal cells. Indian J Med Res 2016;144:852-64.

43. Volarevic V, Nurkovic J, Arsenijevic N, et al. Concise review: Therapeutic potential of mesenchymal stem cells for the treatment of acute liver failure and cirrhosis. Stem Cells 2014;32:2818-23.

44. Devine SM, Bartholomew AM, Mahmud N, et al. Mesenchymal stem cells are capable of homing to the bone marrow of non-human primates following systemic infusion. Exp Hematol 2001;29:244-55.

45. Devine SM, Cobbs C, Jennings M, et al. Mesenchymal stem cells distribute to a wide range of tissues following systemic infusion into nonhuman primates. Blood 2003;101:2999-3001.

46. Barbash IM, Chouraqui P, Baron J, et al. Systemic Delivery of Bone Marrow-Derived Mesenchymal Stem Cells to the Infarcted Myocardium: Feasibility, Cell Migration, and Body Distribution. Circulation 2003;108:863-8.

47. Kraitchman DL, Tatsumi M, Gilson WD, et al. Dynamic Imaging of Allogeneic Mesenchymal Stem Cells Trafficking to MyocardialInfarction. Circulation 2005;112:1451-61.

48. Saito T, Kuang J, Bittira B, et al. Xenotransplant cardiac chimera: immune tolerance of adult stem cells. Ann Thorac Surg 2002;74:19-24.

49. Zhang S, Lv C, Yang X, et al. Corticosterone Mediates the Inhibitory Effect of Restraint Stress on the Migration of Mesenchymal Stem Cell to Carbon Tetrachloride-Induced Fibrotic Liver by Downregulating CXCR4/7 Expression. Stem Cells Dev 2015;24:587-96.

50. Honczarenko M, Le Y, Swierkowski M, et al. Human 
bone marrow stromal cells express a distinct set of biologically functional chemokine receptors. Stem Cells 2006;24:1030-41.

51. Rombouts WJ, Ploemacher RE. Primary murine MSC show highly efficient homing to the bone marrow but lose homing ability following culture. Leukemia 2003;17:16070.

52. Strioga M, Viswanathan S, Darinskas A, et al. Same or Not the Same? Comparison of Adipose Tissue-Derived Versus Bone Marrow-Derived Mesenchymal Stem and Stromal Cells. Stem Cells Dev 2012;21:2724-52.

53. De Becker A, Riet IV. Homing and migration of mesenchymal stromal cells: How to improve the efficacy of cell therapy? World J Stem Cells 2016;8:73-87.

54. Ryan JM, Barry FP, Murphy JM, et al. Mesenchymal stem cells avoid allogeneic rejection. J Inflamm (Lond) 2005;2:8.

55. Chivu M, Dima S, Stancu C, et al. In vitro hepatic differentiation of human bone marrow mesenchymal stem cells under differential exposure to liver-specific factors. Transl Res 2009;154:122-32.

56. Kuo TK, Hung SP, Chuang CH, et al. Stem Cell Therapy for Liver Disease: Parameters Governing the Success of Using Bone Marrow Mesenchymal Stem Cells. Gastroenterology 2008;134:2111-21, 2121.e1-3.

57. Tao XR, Li WL, Su J, et al. Clonal mesenchymal stem cells derived from human bone marrow can differentiate into hepatocyte-like cells in injured livers of SCID mice. J Cell Biochem 2009;108:693-704.

58. Sato Y, Araki H, Kato J, et al. Human mesenchymal stem cells xenografted directly to rat liver are differentiated into human hepatocytes without fusion. Blood 2005;106:756-63.

59. Aithal AP, Bairy LK, Seetharam RN, et al. Therapeutic potential of human bone marrow-derived mesenchymal stromal cells in combination with silymarin against carbon tetrachloride induced liver cirrhosis in Wistar rats. JKIMSU 2017;6:38-49.

60. El-Ansary M, Abdel-Aziz I, Mogawer S, et al. Phase II Trial: undifferentiated versus differentiated autologous mesenchymal stem cells transplantation in Egyptian patients with HCV induced liver cirrhosis. Stem Cell Rev Rep 2012;8:972-81.

61. Kharaziha P, Hellström PM, Noorinayer B, et al. Improvement of liver function in liver cirrhosis patients after autologous mesenchymal stem cell injection: a phase I-II clinical trial. Eur J Gastroenterol Hepatol 2009;21:1199-205.

62. Mohamadnejad M, Alimoghaddam K, Mohyeddin-
Bonab M, et al. Phase 1 trial of autologous bone marrow mesenchymal stem cell transplantation in patients with decompensated liver cirrhosis. Arch Iran Med 2007;10:459-66. Erratum in: Arch Iran Med 2008;11:135.

63. Williams AR, Hare JM. Mesenchymal stem cells: biology, pathophysiology, translational findings, and therapeutic implications for cardiac disease. Circ Res 2011;109:923-40.

64. Tang J, Xie Q, Pan G, et al. Mesenchymal stem cells participate in angiogenesis and improve heart function in rat model of myocardial ischemia with reperfusion. Eur J Cardiothorac Surg 2006;30:353-61.

65. Grinnemo KH, Mansson A, Dellgren G, et al. Xenoreactivity and engraftment of human mesenchymal stem cells transplanted into infarcted rat myocardium. J Thorac Cardiovasc Surg 2004;127:1293-300.

66. Noiseux N, Gnecchi M, Lopez-Ilasaca M, et al. Mesenchymal stem cells overexpressing Akt dramatically repair infarcted myocardium and improve cardiac function despite infrequent cellular fusion or differentiation. Mol Ther 2006; 14:840-50.

67. Shake JG, Gruber PJ, Baumgartner WA, et al. Mesenchymal stem cell implantation in a swine myocardial infarct model: engraftment and functional effects. Ann Thorac Surg 2002;73:1919-25.

68. Toma C, Pittenger MF, Cahill KS, et al. Human mesenchymal stem cells differentiate to a cardiomyocyte phenotype in the adult murine heart. Circulation 2002;105:93-98.

69. Chen SL, Fang W, Ye F, et al. Effect on left ventricular function of intracoronary transplantation of autologous bone marrow mesenchymal stem cell in patients with acute myocardial infarction. Am J Cardiol 2004;94:92-95.

70. Hare JM, Traverse JH, Henry TD, et al. A randomized, double-blind, placebo-controlled, dose-escalation study of intravenous adult human mesenchymal stem cells (prochymal) after acute myocardial infarction. J Am Coll Cardiol 2009;54:2277-86.

71. Kunter U, Rong S, Djuric Z, et al. Transplanted mesenchymal stem cells accelerate glomerular healing in experimental glomerulonephritis. J Am Soc Nephrol 2006;17:2202-12.

72. Ninichuk V, Gross O, Segerer S, et al. Multipotent mesenchymal stem cells reduce interstitial fibrosis but do not delay progression of chronic kidney disease in collagen4A3-deficient mice. Kidney Int 2006;70:121-9.

73. Alfarano C, Roubeix C, Chaaya R, et al. Intraparenchymal injection of bone marrow mesenchymal stem cells reduces kidney fibrosis after ischemia-reperfusion in cyclosporine 
immunosuppressed rats. Cell Transplant 2012;21:2009-19.

74. Herrera MB, Bussolati B, Bruno S, et al. Mesenchymal stem cells contribute to the renal repair of acute tubular epithelial injury. Int J Mol Med 2004;14:1035-41.

75. Zoja C, Garcia PB, Rota C, et al. Mesenchymal stem cell therapy promotes renal repair by limiting glomerular podocyte and progenitor cell dysfunction in adriamycininduced nephropathy. Am J Physiol Renal Physiol 2012;303:F1370-81.

76. Wise AF, Ricardo SD. Mesenchymal stem cells in kidney inflammation and repair. Nephrology 2012;17:1.

77. Tang HL, Wang ZG, Li Q, et al. Targeted delivery of bone mesenchymal stem cells by ultrasound destruction of microbubbles promotes kidney recovery in acute kidney injury. Ultrasound Med Biol 2012;38:661-9.

78. Lee HY, Hong IS. Double-edged sword of mesenchymal stem cells: Cancer-promoting versus therapeutic potential. Cancer Sci 2017;108:1939-46.

79. Kraus KH, Kirker-Head C. Mesenchymal stem cells and bone regeneration. Vet Surg 2006;35:232-42.

80. Hernigou P, Poignard A, Beaujean F, et al. Percutaneous autologous bone-marrow grafting for nonunions: influence of the number and concentration of progenitor cells. J Bone Joint Surg Am 2005;87:1430-7.

81. Volkman R, Offen D. Concise review: mesenchymal stem cells in neurodegenerative diseases. Stem Cells 2017;35:1867-80.

82. Keilhoff G, Goihl A, Stang F, et al. Peripheral nerve tissue engineering: autologous Schwann cells vs. transdifferentiated mesenchymal stem cells. Tissue Eng 2006;12:1451-65.

83. Colpo GD, Ascoli BM, Wollenhaupt-Aguiar B, et al. Mesenchymal stem cells for the treatment of neurodegenerative and psychiatric disorders. An Acad Bras Cienc 2015;87:1435-49.

84. Moviglia GA, Fernandez Vina R, Brizuela JA, et al: Combined protocol of cell therapy for chronic spinal cord injury. Report on the electrical and functional recovery of two patients. Cytotherapy 2006;8:202-9.

85. Koç ON, Day J, Nieder M, et al. Allogeneic mesenchymal stem cell infusion for treatment of metachromatic leukodystrophy (MLD) and Hurler syndrome (MPS-IH). Bone Marrow Transplant 2002;30:215-22.

86. Uccelli A, Moretta L, Pistoia V. Mesenchymal stem cells in health and disease. Nat Rev Immunol 2008;8:726-36.

87. Duijvestein M, Vos AC, Roelofs $\mathrm{H}$ et al. Autologous bone marrow-derived mesenchymal stromal cell treatment for refractory luminal Crohn's disease: results of a phase I study. Gut 2010;59:1662-9.

88. Liang J, Zhang H, Hua B, et al. Allogenic mesenchymal stem cells transplantation in refractory systemic lupus erythematosus: a pilot clinical study. Ann Rheum Dis 2010;69:1423-9.

89. Liang J, Gu F, Wang H, et al. Mesenchymal stem cell transplantation for diffuse alveolar hemorrhage in SLE. Nat Rev Rheumatol 2010;6:486-9.

90. Ansboro S, Roelofs AJ, De Bari C. Mesenchymal stem cells for the management of rheumatoid arthritis: immune modulation, repair or both? Curr Opin Rheumatol 2017; 29:201-7.

91. Yamout B, Hourani R, Salti H, et al. Bone marrow mesenchymal stem cell transplantation in patients with multiple sclerosis: a pilot study. J Neuroimmunol 2010;227:185-9.

92. Lee T. Stem cell therapy independent of stemness. World J Stem Cells 2012;4:120-4.

93. Li J, Tao R, Wu W, et al. 3D PLGA Scaffolds Improve Differentiation and Function of Bone Marrow Mesenchymal Stem Cell-Derived Hepatocytes. Stem Cells Dev 2010;19:1427-36.

94. Ong SY, Dai H, Leong KW. Inducing hepatic differentiation of human mesenchymal stem cells in pellet culture. Biomaterials 2006;27:4087-97.

95. Piryaei A, Valojerdi MR, Shahsavani M, et al. Differentiation of Bone Marrow-derived Mesenchymal Stem Cells into Hepatocyte-like Cells on Nanofibers and Their Transplantation into a Carbon TetrachlorideInduced Liver Fibrosis Model. Stem Cell Rev Rep 2011;7:103-18.

96. Costa RH, Kalinichenko VV, Holterman AX, et al. Transcription factors in liver development, differentiation, and regeneration. Hepatology 2003;38:1331-47.

97. Aggarwal S, Pettinger MF. Human mesenchymal stem cells modulate allogeneic immune cell responses. Blood 2005;105:1815-22.

98. Sato K, Ozaki K, Oh I, et al. Nitric oxide plays a critical role in suppression of T-cell proliferation by mesenchymal stem cells. Blood 2007;109:228-34.

99. Chabannes D, Hill M, Merieau E, et al. A role for heme oxygenase- 1 in the immunosuppressive effect of adult rat and human mesenchymal stem cells. Blood 2007;110:3691-4.

100. Caplan AI, Dennis JE. Mesenchymal stem cells as trophic mediators. J Cell Biochem 2006;98:1076-84.

101.Aithal AP, Bairy LK, Seetharam RN, et al. Human bone marrow derived mesenchymal stromal cells in 
combination with silymarin regulate hepatocyte growth factor expression and genotoxicity in carbon tetrachloride induced hepatotoxicity in Wistar rats. J Cell Biochem 2019;120:13026-36.

doi: $10.21037 /$ sci-2020-036

Cite this article as: Aithal AP, Bairy LK, Seetharam RN. Safety and therapeutic potential of human bone marrow-derived mesenchymal stromal cells in regenerative medicine. Stem Cell Investig 2021;8:10.
102.Saeedi P, Halabian R, Imani Fooladi AA. A revealing review of mesenchymal stem cells therapy, clinical perspectives and Modification strategies. Stem Cell Investig 2019;6:34. 